\title{
The Way That Companies Should Manage Their Human Resources As Their Most Important Asset: Empirical Investigation
}

Abdalla Hagen, (E-mail: hagengrambling@yahoo.com), Grambling State University

Igwe Udeh, (E-mail: udehi@alpha0.gram.edu), Grambling State University

Macil Wilkie, (E-mail: Wilkie@alpha0.gram.edu), Grambling State University

\begin{abstract}
Although research reveals a direct relationship between a company's success and its commitment to management practices that treat its people as assets, trends in management practice are moving away from these principles. This study provides a sound business case confirming that the way a company manages its people is a real and enduring source of competitive advantage. Drawing on their practical experience, the surveyed CEOs agree that the seven management practices (selective hiring, extensive training, employment security, self-management teams and decentralization, comparatively high compensation contingent on organizational performance, reduction of status differences, and sharing information) suggested in this study are the way that companies should manage their people as their most important asset. However, there are differences in the ranking order of management practices between CEOs and Pffer and Veiga (1999).
\end{abstract}

\section{Introduction}

6 ver the past decade, several studies (e.g., Cascio, 1991; Arthur, 1994; Huselid, 1995; Delery \& Doty, 1996; Pfeffer, 1998; Hagen, Udeh, \& Hassan, 2001) conducted within and across many industries demonstrate that enormous economic returns were obtained through the implementation of high commitment management practices. Furthermore, much of this research serves to validate earlier writing on participative management and employee involvement. But even as these research results pile up, trends in actual management practice are, in many instances, moving in a direction exactly opposite to what this growing body of evidence prescribes. Moreover, this disjuncture between knowledge and management practice is occurring at the same time that organizations, confronted with a very competitive environment, are frantically looking for some magic principle that will provide sustained success, at least over some reasonable period of time (Pfeffer, 1998).

Rather than putting their people first, Pfeffer and Veiga (1999) indicate that many organizations have sought solutions to competitive challenges in places and means that have not been very productive. Such organizations treat their businesses as portfolios of assets to be bought and sold in an effort to find the right competitive niche, downsizing and outsourcing in a risky attempt to shrink or transact their way to profit, and doing a myriad of other things that weaken or destroy their organizational culture in order to minimize labor costs. This study extends Pfeffer and Veiga's (1999) study to provide a sound business case confirming that the way that an organization manages its human resources is a real and enduring source of competitive advantage. The study also examines American CEOs' perceptions toward seven practices that affect organizational success.

Readers with comments or questions are encouraged to contact the authors via email. 


\section{Irrefutable Evidence}

CEOs frequently say, "Don't just give me anecdotes specifically selected to make some point; show me the evidence!" Fortunately, there is a substantial and rapidly expanding body of evidence that speaks to the strong connection between how firms manage their people and the economic results achieved. This evidence is drawn from studies of 5-year survival rates of initial public offerings; studies of profitability and stock price in large samples of companies from multiple industries; and detailed research on the automobile, apparel, semiconductor, steel manufacturing, oil refining, and service industries. It shows that substantial gains can be obtained by implementing high performance management practices (Pfeffer, 1998).

According to an award-winning study of high performance work practices of 968 firms representing all major industries, a one standard deviation increase in the use of such practices is associated with a 7.05 percent decrease in turnover and, on a per employee basis, $\$ 27,044$ more in sales and $\$ 18,641$ and $\$ 3,814$ more in market value and profits, respectively (Huselid, 1995). That is an $\$ 18,000$ increase in stock market value per employee! A subsequent study conducted on 702 firms in 1996 found even larger economic benefits: A one standard deviation improvement in the human resources system was associated with an increase in shareholder wealth of $\$ 41,000$ per employee, about a 14 percent market value premium (Huselid \& Becker, 1997).

These results are not unique to firms operating in the United States. Similar results were obtained in a study of more than one hundred German companies operating in ten industrial sectors. The study found a strong link between investing in employees and stock market performance. Companies place workers at the core of their strategies produce higher long-term returns to shareholders than their peers (Bilmes, Wetzker, \& Xhonneux, 1997).

One of the clearest demonstrations of the causal effect of management practices on performance comes from a study of the five-year survival rates of 136 non-financial companies that initiated their public offering in the U.S. stock market in 1988. By 1993, only 60 percent of these companies were still in existence. The empirical analysis demonstrated that with other factors such as size, industry, and even profits statistically controlled, both the value the firm placed on human resources-such as whether the company cited employees as a source of competitive advantage-and how the organization rewarded people-such as stock options for all employees and profit sharing-were significantly related to the probability of survival. Moreover, the results were substantively important. The difference in survival probability for firms one standard deviation above and one standard deviation below the mean (in the upper 16 percent and the lower 16 percent of all firms in the sample) on valuing human resource was almost 20 percent. The difference in survival, depending on where the firm scored on rewards, was even more dramatic, with a difference in five-year survival probability of 42 percent between firms in the upper and lower tails of the distribution (Welbourne \& Andrews, 1996).

Scholars from different disciplines have suggested various conceptual frameworks as explanations for the links between human resource management (HRM) practices and organizational outcomes. For example, Pfeffer (1998) claimed that employee participation and empowerment job design (team-based production system, extensive employee training, performance-contingent incentive compensation, and others) are widely believed to improve the performances of organizations. Similarly, Huselid (1995) concluded that HRM practices affect turnover, productivity, and financial performance of organizations. According to Delery and Doty (1996), HRM practices have the most significant effects on organizational outcomes such as productivity, turnover, and a firm's financial performance.

How can such substantial benefits in profit, quality, and productivity occur? Essentially, these tremendous gains come about because high performance management practices provide a number of important sources for enhanced organizational performance. Simply put, people work harder because of the increased involvement and commitment that comes from having more control and say in their work; people work smarter because they are encouraged to build skills and competence; and people work more responsibly because more responsibility is placed in the hands of employees farther down the organizational hierarchy. These practices do not work because of some mystical process, but because they are grounded in sound social science principles that have been shown to be effective by a great deal of evidence (Pfeffer \& Veiga, 1999). 


\section{Suggested Management Practices}

Hagen, Hassan, and Maghrabi (2002) concluded that not all HRM practices have the same effect on organizational outcomes. The authors attested that while some HRM practices have a significant effect, others have a marginal effect. Based on related literature, personal observation, and experience, Pfeffer and Veiga (1999) developed a set of seven dimensions that seem to characterize most, if not all, of the systems producing profits through human resources. Each one of these practices is briefly summarized below.

\subsection{Employment Security}

Employment security has been emphasized as an important dimension by most researchers on the effects of high performance management systems (Dressler, 1999). In his cross-national review, Locke (1995) proposes that innovations in work practices or other forms of worker-management cooperation or productivity improvement are not likely to be sustained over time when workers fear that by increasing productivity they will work themselves out of their jobs. Pfeffer and Veiga (1999) suggest that the idea of providing employment security in today's competitive world seems impossible and very much at odds with what most firms seem to be doing.

However, employment security is fundamental to the implementation of most other high performance management practices. For example, when General Motors wanted to implement new work arrangements in its innovative Saturn plant in the 1990s, it guaranteed its people job security, except in the most extreme circumstances. When New United Motors Manufacturing firm was formed to operate the Fremont automobile assembly plant, it also offered its people job security (Kelleher, 1997).

Assurance of job security has various benefits. One advantage to firms is the workers' free contribution of knowledge and their efforts to enhance productivity. A second advantage is the decreased likelihood that they will lay off employees during downturns. The benefit from the second advantage to firms is as follows: In the absence of a commitment to retain the work force (either through pledges about employment security or through employment obligations contractually negotiated with a union) firms may lay off employees too quickly and too readily at the first sign of financial difficulty. This constitutes a cost for firms that have done a good job of selecting, training, and developing their workforce because layoffs put important strategic assets on the street for the competition to employ (Pfeffer \& Veiga, 1999).

According to Southwest Airlines, one of its most important tools for building employee partnership is job security and a stimulating work environment. Although there were times when Southwest could have made substantially more profits in the short-term if the company had furloughed people, Southwest didn't. Southwest was looking at its employees' and its longer-term interests. In addition, providing job security imposes additional discipline on the company. If a company's goal is to avoid layoffs, it hires very sparingly. As a result, Southwest Airlines' commitment to job security has actually helped the company keep its labor force smaller and more productive than those of its competitors (Southwest Airlines, 1999).

\subsection{Selective Hiring}

Companies that are serious about obtaining profits through people will expend the effort required to ensure that they recruit the right people in the first place. Selective hiring requires several things (Pfeffer \& Veiga, 1999).

First, the organization needs to have a large applicant pool from which to select. A good example is Southwest Airlines. In 1993, the company received about 98,000 job applications, interviewed 16,000 people, and hired 2,700. In 1994, applications increased to more than 125,000 for 4,000 hires. While some organizations see processing this many job inquiries as an unnecessary expense, Southwest sees it as a necessary first step (Southwest Airlines, 1999). 
Second, the organization needs to be clear about what are the most critical skills and attributes needed in its applicant pool. At Southwest, applicants for flight attendant positions are evaluated on the basis of initiative, judgment, adaptability, and ability to learn. These attributes are assessed in part from interview questions that evoke specific instances of these attributes (O’Reilly, 1996).

Third, the skills and abilities sought need to be carefully considered and consistent with the particular job requirements and the organization's approach to its market. For example, Enterprise Rent-A-Car is today's largest car rental company in the United States, and has expanded at a rate between 25 and 30 percent a year for the past 11 years. It has grown by pursuing a high customer service strategy and emphasizing sales of rental car services to repair garage customers. In a low-wage, often unionized, and seemingly low-employee-skill industry, virtually all of Enterprise's employees are college graduates. But these people are hired primarily for their sales skills and personality and their willingness to provide good service, not for their academic performance (O'Reilly, 1996).

Fourth, organizations should screen primarily on important attributes that are difficult to change through training and should emphasize qualities that actually differentiate among those in the applicant pool. For example, interviewers at PeopleSoft (a producer of human resource management software) ask very little about personal or academic background, except about learning experiences from school and work. Rather, the interviews focused mostly on whether the applicant sees himself or herself as team-oriented or as an individual achiever. Moreover, the people interviewing the applicant present a consistent picture of the values that are shared among employees at PeopleSoft. Such a selection process is more likely to produce cultural fit (O'Reilly, Chatman, \& Caldwell, 1991; Chatman, 1991).

\subsection{Self-Managed Teams And Decentralization As Basic Elements Of Organizational Design}

Systematic studies attest to the effectiveness of teams as a principle of organizational design. Team-based organizations also are largely successful in having all of the people in the firm feel accountable and responsible for the operation and success of the enterprise, not just a few people in senior management positions. This increased sense of responsibility stimulates more initiative and effort on the part of everyone involved. In addition, teams permit removal of layers of hierarchy and absorption of administrative tasks previously performed by specialists, avoiding the enormous costs of having people whose sole job is to watch people who watch other people do the work (Farren, 1999; Gregory, 1999). For example, the implementation of teams in Honeywell's defense avionics plant led to credits improvement, on-time delivery, from 59 percent in the late 1980s to 99 percent in the first quarter of 1996 (The Wall Street Journal, 1996).

Whole Foods Market (a natural foods grocery store chain) also attributes much of its success to its teambased organization. Between 1991 and 1996, the company enjoyed sales growth of 864 percent and net income growth of 438 percent as it expanded, in part through acquisitions as well as through internal growth, from 10 to 68 stores. The stores are organized into self-managing work teams that are responsible and accountable for their own performance (Whole Foods Market Inc., 1995 Annual Report). In addition, teams permit employees to pool their ideas to come up with better and more creative solutions to problems. For example, teams at Saturn and at Chrysler Corporation's Jefferson North plant, provide a framework in which workers more readily help one another and more freely share their production knowledge--the innumerable 'tricks of the trade' that are vital in any manufacturing process (Shaiken, Lopez, \& Mankita, 1997).

Team-based organizations are not simply a made-only-in-America phenomenon. For example, Vancom Zuid-Limburg, a joint venture in the Netherlands, operates a public bus company. This company has enjoyed very rapid growth in ridership and has been able to win transport concessions by offering more services at the same price as its competitors. The key to this success lies in its use of self-managed teams and the consequent savings in management overhead. Vancom was able to win transport contracts mainly because of its very low overhead costs (Van Beusekom, 1996). 


\subsection{Comparatively High Compensation Contingent On Organizational Performance}

It is often argued that high compensation is a consequence of organizational success, rather than its progenitor, and that high compensation (compared with the average) is possible only in certain industries that either face less competition or have particularly highly educated employees. In fact, neither of these statements is correct. Frequently, successful firms can afford to pay more, but high pay can also produce economic success (Lewis, Goodman, \& Fandt, 2001).

Pathmark, a large grocery store chain in the eastern United States is an example. In 1972, the company had about 90 days to live, and was in desperate financial situation. The new manager, who assumed leadership in 1972, discovered that 120 store managers in the chain were paid less than the butchers, who were unionized. He decided that the store managers were vital to the chain's success and its ability to accomplish a turnaround. Consequently, he gave the store managers a substantial raise, about 40 to 50 percent. Subsequent success of the chain was attributed to improving performance instead of complaining about their pay (Pfeffer \& Veiga, 1999).

The idea that only certain jobs or industries can or should pay high wages is belied by the example of many firms. Home Depot has been successful and profitable, and its stock price has shown exceptional returns. Even though the chain emphasizes everyday low pricing as an important part of its business strategy and operates in a highly competitive environment, it pays its staff comparatively well for the retail industry, hires more experienced people with building industry experience, and expects its sales associates to provide a higher level of individual customer service (Pfeffer \& Veiga, 1999).

Contingent compensation also figures prominently in most high performance work systems. Such compensation can take a number of different forms, including gain sharing, profit sharing, stock ownership, pay for skill, or various forms of individual or team incentives. Wal-Mart, AES Corporation, Southwest Airlines, Whole Foods Markets, Microsoft, and many other successful organizations encourage share ownership. When employees are owners, they act and think like owners. However, little evidence suggests that employee ownership, by itself, affects organizational performance. Rather, employee ownership works best as part of a broader philosophy or culture that incorporates other practices. Merely putting in ownership schemes without providing training, information sharing, and delegation of responsibility will have little effect on performance. Even if people are more motivated by their share ownership, they don't necessarily have the skills, information, or power to do anything with that motivation (Pfeffer \& Veiga, 1999).

\subsection{Extensive Training Programs And Development}

Training is often seen as a frill in many U.S. organizations, something to be reduced to make profit aims in times of economic stringency. Studies of firms in the United States consistently provide evidence of inadequate levels of training. Even when there is training, it focuses on special skills rather than generalist competence and organizational culture. Although knowledge and skill are critical for organizational success, few organizations act on this insight. Training is an essential component of high performance work systems because these systems rely on frontline employee skill and initiative to identify and resolve problems, to initiate changes in work methods, and to take responsibility for quality. All of this requires a skilled and motivated work force that has the capability to perform the required tasks (Grossman \& Mangus, 1989; Lawler, Mohrman, \& Ledford, 1992).

Men's Wearhouse (an off-price specialty retailer of men's tailored business attire and accessories) discovered that training can be a source of competitive advantage if it is wisely used. Its 1995 annual report revealed that Men's Warehouse had achieved compounded annual growth rates in revenues and net earnings of 32 and 41 percent, respectively, and that the value of its stock had increased by approximately 400 percent. The company attributes its success to how it treats its people and particularly to the emphasis it has placed on training, an approach that separates it from many of its competitors. The company built a 35,000 square foot training center in Fremont, California, its headquarters. During the winter, experienced store personnel come back to headquarters in groups of about 30 for a three or four-day retraining program (Men's Wearhouse Annual report, 2001). 
While training is an investment in the organization's staff, some firms emphasize training as a matter of faith and because of their belief in the connection between people and profits. For example, Motorola does a poor job of measuring its return on training. Although the company has been mentioned as reporting a $\$ 3$ return for every $\$ 1$ invested in training, an official from Motorola's training group said that the company did not know where these numbers came from and that the company is notoriously poor at evaluating its $\$ 170$ million investment in training. However, the firm mandates forty hours of training per employee per year, and believes that the effects of training are both difficult to measure and expensive to evaluate. Training is part and parcel of an overall management process and is evaluated in that light (Pfeffer \& Veiga, 1999).

\subsection{Reduction Of Status Differences}

The fundamental premise of high performance management systems is that organizations perform at a higher level when they are able to tap the ideas, skill, and effort of all of their people. In order to help make all organization members feel important and committed, most high commitment management systems attempt to reduce the status differences that separate individuals and groups and cause some to feel less valued. This notion can be accomplished through the use of language and labels, physical space, dress, and substantively, in the reduction of the organization's degree of wage inequality, particularly across levels (Dessler, 1999).

At the New United Motor Manufacturing firm, everyone wears the same colored smock; executive dining rooms and reserved parking don't exist. At Kingston Technology, a private firm manufacturing add-on memory modules for personal computers, the two cofounders sit in open cubicles and do not have private secretaries. Status differences are also reduced, and a sense of common fate developed, by limiting the difference in compensation between senior management and other employees (Pfeffer \& Veiga, 1999).

When Southwest Airlines negotiated a five-year wage freeze with its pilots in exchange for stock options and occasional profitability bonuses, the CEO of Southwest, Herb Kelleher, agreed to freeze his annual base salary at $\$ 395,000$ for four years from $\$ 500,000$ per year, including base and bonus. Sam Walton, the founder and chairman of Wal-Mart, was one of the most underpaid CEOs in the United States. Kelleher and Walton were not poor; each owned stock in the company. Stock ownership was also encouraged for their employees. Having an executive's fortune rise and fall together with those of the other employees differs significantly from providing large bonuses and substantial salaries for executives even as the stock price languishes and people are being laid off (The Economist, 1995).

\subsection{Sharing Information}

Information sharing is a basic and essential component of high performance work systems. The sharing of information on such things as financial performance, strategy, and operational measures conveys to the organization's people that they are trusted. The CEO of Whole Foods Markets demonstrated once, " if the firm is trying to create a high-trust organization in which people are all-for-one and one-for-all, such a firm can't have secrets." Whole Foods Markets is another example. The firm shares detailed financial and performance information with every employee, including individual salary information. Every Whole Foods store has a book that lists the previous year's salary and bonus of all 6,500 employees (Fisherman, 1996).

Even motivated and trained people cannot contribute to enhancing organizational performance if they don't have information on important dimensions of performance and training on how to use and interpret that information (Dessler, 1999). The famous case of Springfield ReManufacturing Corporation (SRC) is a good example that illustrates this assertion. On February 1, 1983, SRC was created when plant's management and employees purchased an old International Harvester plant in a financial transaction that consisted of about $\$ 100,000$ in equity and $\$ 8.9$ million in debt, which makes it one of the most leveraged of all buyouts. The plant manager at that time knew that if the plant was to succeed, all employees had to do their best, and had to share all their wisdom and ideas for enhancing the plant's performance. That manager came up with a system called "open-book management," that has become so popular that SRC now makes money by running seminars on it (Pfeffer \& Veiga, 1999). 
When General Motors canceled an order in 1986 that represented about 40 percent of SRC's business for the coming year, the firm averted layoffs by providing its people with information on what had happened and letting them figure out how to grow the company and achieve the productivity improvements that would avoid layoffs. SRC has since enjoyed tremendous financial success (Pfeffer \& Veiga, 1999).

\section{Research Methods}

Research methods used in this study included survey questionnaire, sample and data collection, and statistical techniques. Each method was carried out according to the following procedures:

\section{Survey Questionnaire}

The survey questionnaire was developed by the researchers of this study and included seven management practices and four barriers. The items and statements utilized in this survey were adapted from Pfeffer and Veiga's (1999) study. The first section of this survey included 29 statements measuring management practices that treat organizational human resources as the most valuable asset. The second section included demographic information (age, education, experience) and organizational variables (age, size, and type of industry).

Statements were categorized under seven practices as follows: employee security (4 items), selective hiring (5 items), self management teams and decentralization ( 5 items), comparatively high compensation contingent on organizational performance (4 items), extensive training programs and development (6 items), reduction of status differences ( 2 items), and sharing information ( 3 items). Each statement has a five-point Likert response format ranging from Astrongly disagree (1)@ to A strongly agree (5).@ The two scale points of Astrongly disagree and disagree@ were combined as the lower points. The two scale points of Astrongly agree and agree ${ }^{-}$were combined as the higher points. The scale points of Aneither disagree nor agree@ were excluded from data analysis. An alpha coefficient of 0.88 was obtained for the overall scale scores measuring the ranking order of the components measuring management practices and barriers.

A pilot study was conducted to test the questionnaire $=\mathrm{s}$ construct validity. The split-half procedure was also used for the internal consistency measure of test reliability, which is obtained by dividing the items into halves and correlating the scores of these halves. The most common procedure is to obtain odd-even reliability by correlating the scores of odd-numbered and even-numbered test items. It was found that the utilized questionnaire is valid and reliable.

This survey elicited opinions from the participating CEOs who actually practiced some or all the suggested seven management practices in their organizational settings. Respondents were asked to assign the degree or the extent of their agreement or disagreement with each of the 29 concerning management practices. The final version of this questionnaire was modified by a confirmatory factor analysis (CFA) conducted to drop statements of factor loading less than .50.

\section{Sample And Data Collection}

The research sample consisted of 500 American CEOs randomly selected from a list of corporations throughout the United States. The sample was derived from a research project concerning strategic leadership practices in this globalization era. CEOs of the participating corporations were mailed a cover letter requesting their participation, the survey questionnaire, a stamped return envelope, and a brief summary of the seven management practices and the four barriers used in this study. Of the 500 mailed questionnaires, $112(22.4 \%)$ were returned to the authors. Of the 112 returned questionnaires, 110 (reducing the response rate 22\% fro 22.4\%) of them were complete and usable. Of the 110 complete and usable questionnaires, there were 14 and 96 for female-male CEOs, respectively. 


\section{Statistical Analysis}

Statistical analysis in this study utilized the Statistical Package for Social Science (SPSS-X) to compute frequencies, means, percentages, and Chi-square. Because of the nominal grouping of the responses, contingency tables and Chi-square were used to test for the independence of the distributions. Confirmatory factor analysis was conducted to ensure that the participants were able to differentiate these items from each other.

\section{The Results Of This Study}

One of our goals was to investigate the factor structure of the scales by incorporating all scales of the seven management practices into a separate confirmatory factor analysis (CFA). The CFA conducted on data collected from the responding CEOs revealed that the measures of the seven management practices and their four barriers were distinguishable from one another. Due to the limited space, the CFAs are not reported in this study. However, both CFAs can be obtained upon request from authors through their published e-mails.

The matrix correlation presented in Table 1 shows moderate correlations among included items. These correlations indicate that the seven management practices are not completely independent. These correlations were expected because the items measuring the seven management practices are related. However, such moderate correlations were not considered a serious problem in previous research (e.g., Hagen, Udeh, and Hassan, 2001).

Table 2 presents the ranking order of the seven management practices, and the percentages of the responses of participating CEOs to these management practices. Data analysis in Table 2 shows an overwhelming majority of the responding CEOs revealing a general consensus that when it comes to managing human resources, organizations should not ignore readily available opportunities to improve and increase their organization's performance.

Table 2 also shows that CEOs have a different ranking order from that of Peffer and Veiga (1999). Probably the decision of CEOs is attributed to the global economy and the new competitive landscape in the $21^{\text {st }}$ century. CEOs consider selective hiring, extensive training programs and development, employment security, comparatively high compensation contingent on organizational performance, self-management teams and decentralization, reduction of status differences, and sharing information as the way that an organization should manage its human resources as the most important asset.

Table 1

Correlation Matrix for the Responses of CEOs to Management Practices

\begin{tabular}{|c|c|c|c|c|c|c|c|}
\hline Management Practices & 1 & 2 & 3 & 4 & 5 & 6 & 7 \\
\hline 1. Employment security & 1.0 & & & & & & \\
\hline 2. Selective hiring & $.12 *$ & 1.0 & & & & & \\
\hline 3. Self-management teams and decentralization & .04 & $.18 *$ & 1.0 & & & & \\
\hline $\begin{array}{l}\text { 4. Comparatively high compensation contingent } \\
\text { on organization's performance }\end{array}$ & $.15^{*}$ & $.12 *$ & $.22 * *$ & 1.0 & & & \\
\hline 5. Extensive training programs and development & .11 & $.28 * *$ & $.14^{*}$ & $.21 *$ & 1.0 & & \\
\hline 6. Reduction of status differences & $.15^{*}$ & $.12 *$ & $.22 * *$ & $.16^{*}$ & .09 & 1.0 & \\
\hline 7. Sharing information & .12 & .09 & $.14 *$ & .08 & .07 & $.12 *$ & 1.0 \\
\hline
\end{tabular}

\footnotetext{
$* \mathrm{P}<.05$

$* * \mathrm{P}<.01$
} 
Table 2

Data Analysis for the Responses of CEOs to the Seven Management Practices

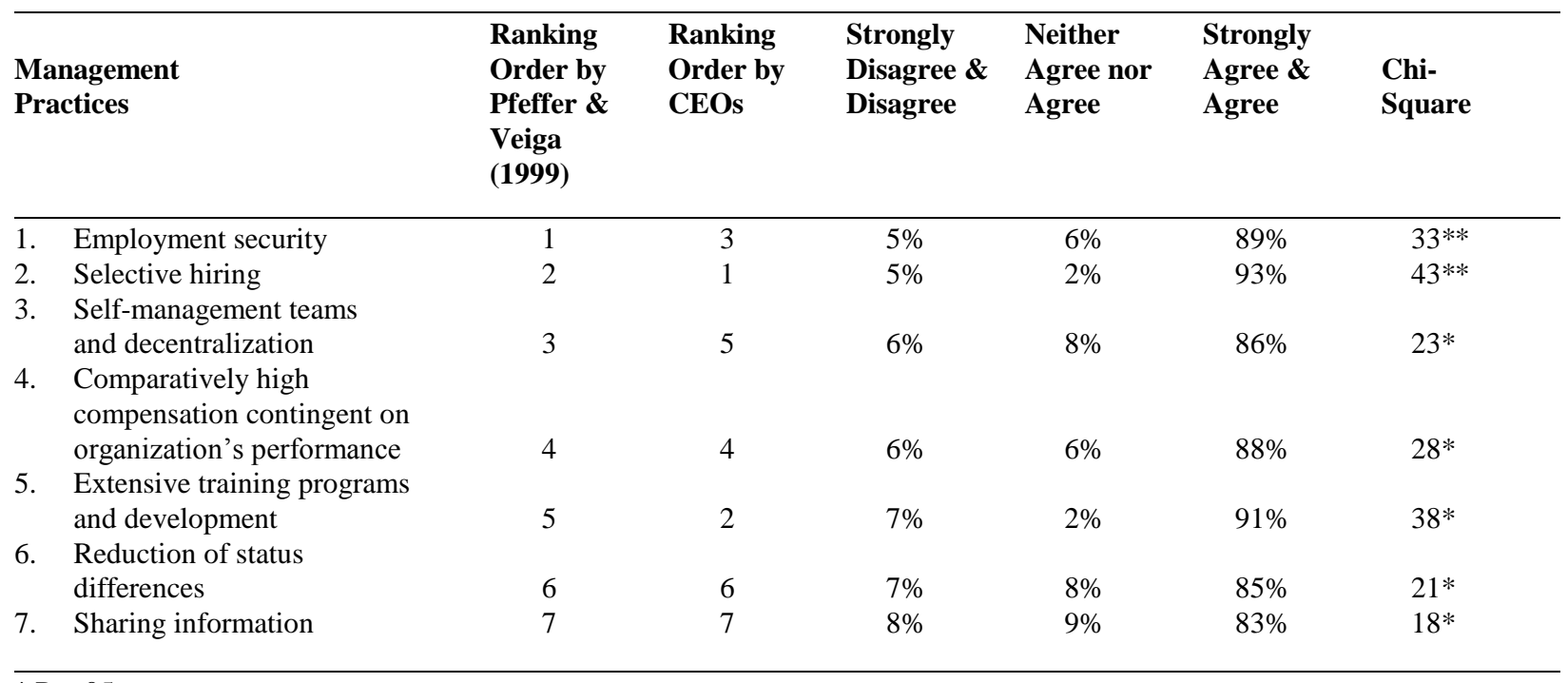

$* \mathrm{P}<.05$

$* * \mathrm{P}<.01$

\section{Discussion}

It is not surprising that the largest majority (93\%) of the participating CEOs assigned the first rank to "selective hiring" because competition in the $21^{\text {st }}$ century's global economy demands a corporate focus on selective hiring. That is, to hire the right person for the right job. CEOs also acknowledge that their organizations need to have a large applicant pool from which to select, to be clear about the most critical skills, to match these skills with the required job and market, and to emphasize qualities that really differentiate among those in the applicant pool.

Ninety one percent of the CEOs assigned the second rank to "extensive training programs and development" requiring organizations to develop, exploit, and protect the intellectual capital in their organizations. They admit that this requirement can be achieved through extensive training programs and development. They consider extensive training programs a source of competitive advantage and an essential component of high performance work systems in their organization. Such training should be provided for employees in the job every few years or as needed. There should be formal training programs to teach new hires the skills they need to perform their jobs. Finally, organizations should provide funded education, workshops, and conventions to develop required employees' skills.

Although the idea of providing "employment security" in the $21^{\text {st }}$ century seems impossible, eighty nine percent assigned this concept the third rank because they still believe that employment security is a fundamental element for employees who expect to stay in their organizations as long as they wish. CEOs also attest to the fact that job security in most organizations is normally not guaranteed, particularly when organizations face economic problems. CEOs also indicate that despite the benefits of employment security, organizations may lay off employees too quickly and too readily at the first sign of financial difficulty.

Eighty eight percent of these CEOs assigned "self-management teams and decentralization" the fourth rank for several reasons. A possible reason is that these CEOs believe that teams permit removal of layers of hierarchy and absorption of administrative tasks previously performed by specialists, saving costs of having people whose sole job is to watch other people do the work. Furthermore, teams permit employees to pool their ideas to come up with better and more creative solutions to problems. Teams also provide a framework in which workers more readily help each other and more freely share their production knowledge. 
Eighty six percent of the CEOs assigned the fifth rank to "comparatively high compensation contingent on organization's performance. They confirm that successful organizations can afford to pay more because high pay produces financial success. CEOs also accept a number of different forms of compensation such as profit sharing, stock ownership, pay for skill, or various forms of individual or team incentives.

When employees are owners, they act and think like owners. Employee ownership works best as a part of a broader culture that incorporates other practices. CEOs warn that just putting in ownership approaches without providing training, information sharing, and delegation of responsibility will have a marginal influence on performance. Even if employees are more motivated by their shared ownership, they do not necessarily have the skills, information, or power to do anything with that motivation.

Eighty five percent of these CEOs gave the sixth rank to "reduction of status differences among employees" in order to make all employees feel important. CEOs agree that reducing such differences can be achieved through the use of language and labels, physical space, dress, and reduction of the organization's degree of wage inequality, particularly across levels, especially between senior management and other employees. Literature reported role models who were pioneer in reducing status differences (e.g., Herb Kelleher and Sam Walton, etc.).

Finally, eighty three percent of CEOs gave the seventh rank to "sharing information" because they view this management practice as a basic component of high performance work systems. CEOs affirm that the sharing of information on such things as financial performance, strategy, and operational measures conveys to the organization's employees that they are trusted. Even motivated and trained people cannot contribute to enhancing organizational performance if they don't have information on important dimensions of performance and training on how to use and interpret that information.

\section{Implications}

Implementing and seeing results of the aforementioned practices takes time. It takes time to train and upgrade workers' skills and even more time to see the economic benefits of this training in reduced turnover and enhanced performance. It takes time to share operating and financial information with people, and to be sure that they understand and know how to use it. Even more time is needed before suggestions and insights can improve business results.

The key to managing people in ways that lead to profits, productivity, innovation, and real organizational learning ultimately lies in the manager's perspective. When managers look at their people, do they see costs to be reduced? Do they see recalcitrant employees prone to opportunism, shirking, and free riding, who can't be trusted and who need to be closely controlled through monitoring, reward, and sanctions? Do they see people performing activities that can and should be contracted out to save labor costs? Or, do they see intelligent, motivated, trustworthy individuals, the most critical and valuable strategic assets their organizations can have? When they look at their people do they see them as the fundamental resources on which their success rests and the primary means of differentiating themselves from the competition? With the right perspective, anything is possible. With the wrong one, change efforts and new programs become gimmicks, and no number of consultants, seminars, and slogans will help.

\section{Conclusions}

The economy will continue to be complex, challenging and filled with competitive opportunities and threats. Effective management practices can help firms compete successfully in this globalization era. Suggested management practices are the ways of how organizations should treat employees as their most valuable asset. There should be barriers and potential challenges encounter CEOs of organizations during the implementation of these management practices. 


\section{Recommendations for Future Research}

Future research should expand this study to include potential barriers to these management practices. This study reported the perceptions of CEOs to these management practices. Future research should also include human resource managers and employees' perceptions to these practices. Are there similarities and/or differences in the perceptions of the three groups to these management practices?

\section{References}

1. Annual Report. 2001. Whole Foods Market, Austin, TX: 3-17.

2. Annual Report. 2001. Men's Wearhouse Fremont, CA: 3.

3. Arthur,J. B. 1994. "Effects of human resource systems on manufacturing performance". Academy of Management Journal, 37: 670-687.

4. Blimes, L., Wetzker, K., and Xhonneux, P. 1997. "Value in human resources". Financial Times, February: 10.

5. Cascio, W. 1991. Costing human resources: The financial impact of behavior in organizations. Boston: PWS.

6. Chatman, J. A. 1991. "Managing people and organizations: Selection and socialization in public accounting firms". Administrative Science Quarterly, 36: 459-484.

7 Delery, J., and Doty, D. 1996. "Modes of theorizing in strategic contingency, and configurational, performance predictions". Academy of Management Journal, 39: 802-834.

8. Dessler, G. 1999. "How to earn your employees' commitment". Academy on Management Executive, 13: 58-66.

9. Farren, C. 1999. "A smart team makes the difference". The Human Resource Professional, 12: 12-16.

10. Fisherman, C. 1996. "Whole Foods teams". Fast Company, April- May: 106.

11. Gregory, A. 1999. "Solving the team building jigsaw". Works Management, 52: 56-59.

12. Grossman, M. E., and Mangus, M. 1989. "The 5.3 billion tab for training”. Personnel Journal, 68: 54-56.

13. Hagen, A., Udeh, I, and Hassan, M. 2001. "Strategic human resources management practices as predictors of organizational profitability variables: Evidence from two countries". Central Business Review, XX: 24-31.

14. Hagen, A., Hassan, M., and Maghrabi, A. 2002. "Assessing the link between strategic human resource management practices and corporate financial performance". International Journal of Manpower, 19: 559-568.

15. Huselid, M. A. 1995. "The impact of human resource management practices on turnover, productivity, and corporate financial performance". Academy of Management Journal, 38: 647.

16. Huselid, M. A., and Becker, B. E. 1997. "The impact of high performance work systems, implementation effectiveness, and alignment with strategy on shareholder wealth". Unpublished paper, Rutgers University, New Brunswick, NJ: 18-19.

17. Kelleher, H. 1997. "A culture of commitment". Leader to Leader, 1: 23.

18. Lawler, E., Mohrman, S., and Ledford, A .1992. Employee involvement and total quality management. San Francisco, CA: Jossey-Bass.

19. Lewis, P. S., Goodman, S. H., and Fandt, P .M. 2001. Management challenges in the $21^{\text {st }}$ century. New York, Ny: Southwest Publising Company.

20. Locke, R. M. 1995. The transformation of industrial relations A cross-national review, in the comparative political economy of industrial relations, eds Kristen S. Wever and Lowell Turner, Madison, WI: Industrial Relations Research Association: 18-19.

21. O'Reilly, B. 1996. "The rent-a-car jocks who made Enterprise \#1". Fortune, 28: 128.

22. O'Reilly, C. A., Chatman, J. A., and Caldwell, D. F. 1991. "People and organizational culture: A profile comparison approach to assessing person-organization fit". Academy of Management Journal, 34: 487-516

23. Pfeffer, J. 1994. "Competitive advantage through people: Understanding the power of the workforce". Boston: Business Harvard School Press.

24. Pfeffer, J., and Veiga, J. 1999. "Putting people first for organizational success". Academy of Management 
Executive, 13: 37-48.

25. Pfeffer, J. 1994. "Competitive advantage through people: Understanding the power of the workforce". Boston: Business Harvard School Press.

26. Pfeffer, J. 1998. "The human equation: Building profits by putting people first". Boston: H BS Press.

27. Shaiken, H., Lopez, S., and Mankita, I. 1997. "Two routes to team production: Sturn and Chrysler compared". Industrial Relations, 36: 31.

28. Southwest Airlines. 1999. Case S-OB-28, Palo. Alto, CA: Graduate School of Business, Stanford University.

29. The Economist. 1995. "Doing the right thing", 20: 64.

30. $\quad$ The Wall Street Journal. 1996. "Work Week”, 28 May: Al.29.

31. Van Beusekom, Mark. 1996. "Participation pays! Cases of successful companies with employee participation". Hague: Netherlands Participation Institute: 7.

32. Welbourne, T., and Andrews, A. 1996. "Predicting performance of initial public offering firms: Should HRM be in the equation?" Academy of Management Journal, 39: 891-919.

Notes 